\title{
Using a Conformal Water Bolus to Adjust Heating Patterns of Microwave Waveguide Applicators
}

\author{
Paul R. Stauffer \\ Thomas Jefferson University \\ Dario B. Rodrigues \\ Thomas Jefferson University \\ Randolph Sinahon \\ Drexel University \\ Lyndsey Sbarro \\ Drexel University \\ Valeria Beckhoff \\ Drexel University \\ Follow this and additional works at: https://jdc.jefferson.edu/radoncfp \\ Part of the Oncology Commons

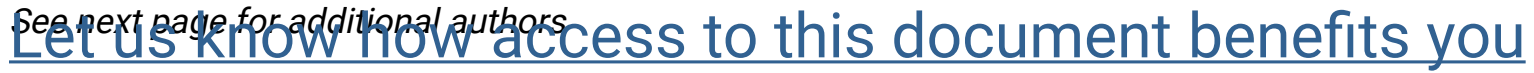

\section{Recommended Citation}

Stauffer, Paul R.; Rodrigues, Dario B.; Sinahon, Randolph; Sbarro, Lyndsey; Beckhoff, Valeria; and Hurwitz, Mark, "Using a Conformal Water Bolus to Adjust Heating Patterns of Microwave Waveguide Applicators" (2017). Department of Radiation Oncology Faculty Papers. Paper 90. https://jdc.jefferson.edu/radoncfp/90

This Article is brought to you for free and open access by the Jefferson Digital Commons. The Jefferson Digital Commons is a service of Thomas Jefferson University's Center for Teaching and Learning (CTL). The Commons is a showcase for Jefferson books and journals, peer-reviewed scholarly publications, unique historical collections from the University archives, and teaching tools. The Jefferson Digital Commons allows researchers and interested readers anywhere in the world to learn about and keep up to date with Jefferson scholarship. This article has been accepted for inclusion in Department of Radiation Oncology Faculty Papers by an authorized administrator of the Jefferson Digital Commons. For more information, please contact: JeffersonDigitalCommons@jefferson.edu. 


\section{Authors}

Paul R. Stauffer, Dario B. Rodrigues, Randolph Sinahon, Lyndsey Sbarro, Valeria Beckhoff, and Mark Hurwitz 


\title{
Using a Conformal Water Bolus to Adjust Heating Patterns of Microwave Waveguide Applicators
}

\author{
Paul R. Stauffer*a ${ }^{\mathrm{a}}$, Dario B. Rodrigues ${ }^{\mathrm{a}}$, Randolph Sinahon ${ }^{\mathrm{b}}$, Lyndsey Sbarro ${ }^{\mathrm{b}}$, Valeria Beckhoff ${ }^{\mathrm{b}}$, \\ Mark D. Hurwitz ${ }^{\mathrm{a}}$ \\ ${ }^{a}$ Radiation Oncology Dept., Thomas Jefferson University, Philadelphia PA USA 19107 \\ ${ }^{\mathrm{b}}$ Biomedical Engineering Dept., Drexel University, Philadelphia PA USA 19105
}

\begin{abstract}
Background: Hyperthermia, i.e., raising tissue temperature to $40-45^{\circ} \mathrm{C}$ for $60 \mathrm{~min}$, has been demonstrated to increase the effectiveness of radiation and chemotherapy for cancer. Although multi-element conformal heat applicators are under development to provide more adjustable heating of contoured anatomy, to date the most often used applicator to heat superficial disease is the simple microwave waveguide. With only a single power input, the operator must be resourceful to adjust heat treatment to accommodate variable size and shape tumors spreading across contoured anatomy.

Methods: We used multiphysics simulation software that couples electromagnetic, thermal and fluid dynamics physics to simulate heating patterns in superficial tumors from commercially available microwave waveguide applicators. Temperature distributions were calculated inside homogenous muscle and layered skin-fat-muscle-tumor-bone tissue loads for a typical range of applicator coupling configurations and size of waterbolus. Variable thickness waterbolus was simulated as necessary to accommodate contoured anatomy. Physical models of several treatment configurations were constructed for comparison of simulation results with experimental specific absorption rate (SAR) measurements in homogenous muscle phantom.

Results: Accuracy of the simulation model was confirmed with experimental SAR measurements of three unique applicator setups. Simulations demonstrated the ability to generate a wide range of power deposition patterns with commercially available waveguide antennas by controllably varying size and thickness of the waterbolus layer.

Conclusion: Heating characteristics of $915 \mathrm{MHz}$ waveguide antennas can be varied over a wide range by controlled adjustment of microwave power, coupling configuration, and waterbolus lateral size and thickness. The uniformity of thermal dose delivered to superficial tumors can be improved by cyclic switching of waterbolus thickness during treatment to proactively shift heat peaks and nulls around under the aperture, thereby reducing patient pain while increasing minimum thermal dose by end of treatment.
\end{abstract}

Keywords: Microwave power deposition, waterbolus coupling, SAR, electromagnetic and thermal modeling

\section{INTRODUCTION}

Numerous clinical trials have demonstrated that hyperthermia (HT) treatment, or raising tumor temperatures to $40-45^{\circ} \mathrm{C}$ for one hour, increases response rates compared to best available radiation (RT) and/or chemotherapy (ChT) treatments alone. ${ }^{1,2}$ Datta et al. (2015) recently reviewed clinical results reported in 38 predominantly randomized two-arm clinical trials involving 3478 patients. ${ }^{3}$ Statistically significant benefit from adding local regional HT to best available RT \pm ChT was demonstrated in 31 clinical trials. Overall complete response was $39.8 \%$ in RT \pm ChT treated tumors and $54.9 \%$ in tumors treated with adjuvant HT, a significant advantage with an odds ratio of 2.3. Still, there were seven clinical trials that reported no significant improvement with hyperthermia. In retrospective analyses, these failures were widely attributed to problems in the quality of hyperthermia treatments due to limitations in heating equipment and thermal dosimetry procedures. ${ }^{4}, 5$ In the years following those early negative trials, there has been considerable development of new heating, thermometry, and treatment planning systems capable of significantly improved control of heat delivery. ${ }^{6-12}$ In addition, there has been a continual updating of quality assurance (QA) procedural guidelines intended to improve treatment quality, ${ }^{13-15}$ including six QA guidelines in the 1980s, eight QA documents in the 1990's, five QA publications in the 2000's, and three guidelines currently in the journal submission cycle. Despite all this

*paul.stauffer@jefferson.edu; phone 1215 503-8825 
development activity, there remains only one clinical microwave hyperthermia system approved by the FDA for superficial hyperthermia in the US and that system was approved prior to the published hyperthermia trials. That system includes a choice of three different size waveguide applicators, each powered by a single $915 \mathrm{MHz}$ input. It is widely considered that the power deposition pattern of a single channel waveguide applicator is fixed and the only possible adjustment in heating pattern is by varying power input or waveguide position over the tumor. Our hypothesis motivating this study is that heating patterns of microwave waveguide applicators can be adjusted during treatment by appropriate changes to the coupling medium, which can be preplanned with electromagnetic and thermal modeling in order to improve the uniformity of heating in superficial tumors.

The objective of this study is to explore methods of adjusting waveguide heating patterns with a long term goal of improving thermal dose uniformity during superficial hyperthermia. We investigate the effects on power deposition patterns of a MA-120 waveguide (Pyrexar Medical - Salt Lake City UT) from adjusting applicator coupling by changing: i) rotation angle of the MA-120 tuning blades, ii) applicator interface (direct contract, air coupling, or dielectric bolus), and iii) lateral dimensions and thickness of the coupling dielectric (i.e. waterbolus). Heating patterns are evaluated with numerical simulations of SAR and resulting temperature distributions in homogeneous muscle and contoured multi-layer tissue models of the human chest. The purpose is to determine the range of heating patterns possible by controlled adjustment of coupling bolus configurations. In order to validate the theoretical modeling, SAR patterns are determined for several treatment configurations with both simulations and experimental measurements using a scanning SAR probe in a tank filled with muscle-mimicking liquid phantom. These studies are summarized in the following sections.

\section{METHODS}

\subsection{The Clinical Problem}

Chest wall recurrence (CWR) of breast carcinoma is a debilitating disease: if not controlled early, it will progress to increasing areas of the patient's skin on the chest, arms, shoulders and back. The patient often presents with recurrent disease that is previously irradiated and thus unable to receive full dose radiation. In such patients, treatment with adjuvant hyperthermia has demonstrated significant improvement in complete response rates over best available treatment with re-irradiation alone. ${ }^{16}$ Similar advantage to adjuvant hyperthermia has been demonstrated for other superficial malignancies, ${ }^{17}$ including malignant melanoma ${ }^{18}$ and head and neck ${ }^{19}$ tumors. A common problem that limits further effectiveness of hyperthermia is the difficulty in incorporating the entire disease within the effective heating area of a single waveguide applicator. Figure 1 shows two examples of chest wall recurrence (CWR) that are typical cases for superficial microwave hyperthermia. The disease extends $<1.5 \mathrm{~cm}$ deep and thus is a match to the penetration capabilities of $915 \mathrm{MHz}$ microwave antennas $(<3 \mathrm{~cm})$. However, the challenge is to couple box-shaped rectangular waveguides - such as the available FDA approved applicators of Figure $\mathbf{2}$ - to a disease that spreads laterally across contoured human anatomy.
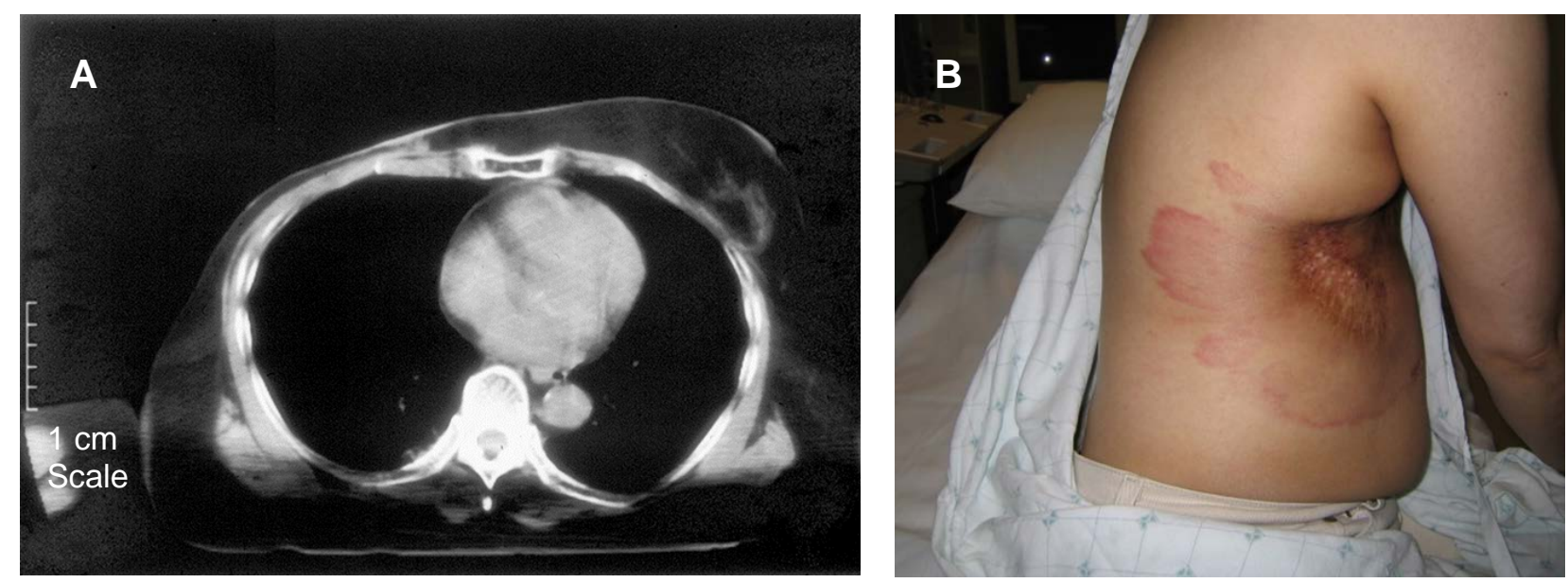

Figure 1 - Two examples of chestwall recurrence (CWR) of breast carcinoma as typical disease target for superficial microwave hyperthermia: A) CT image shows thickened white contrast-enhancing region extending across the skin of the patient's left chest near a mastectomy scar and to a depth of approximately 0.5-1.5 cm; B) Superficial disease extending $<1 \mathrm{~cm}$ deep across the anterior and lateral right chestwall. 
To improve the coupling of microwaves into the contoured human body, a coupling medium with high dielectric constant similar to tissue is desired to fill the space between applicator and skin. Generally, deionized water is circulated through the bolus at a controlled temperature, which serves to cool and control skin temperature as well as to couple microwaves into tissue. For tumors located on flat or gently curving surfaces, a bolus with flexible silicone membrane within a fixed outer frame works effectively to couple the waveguide. However, for convex and sharply contoured surfaces, a conformal bolus is better to couple a waveguide to anatomic contours typical of the lateral chestwall or neck.
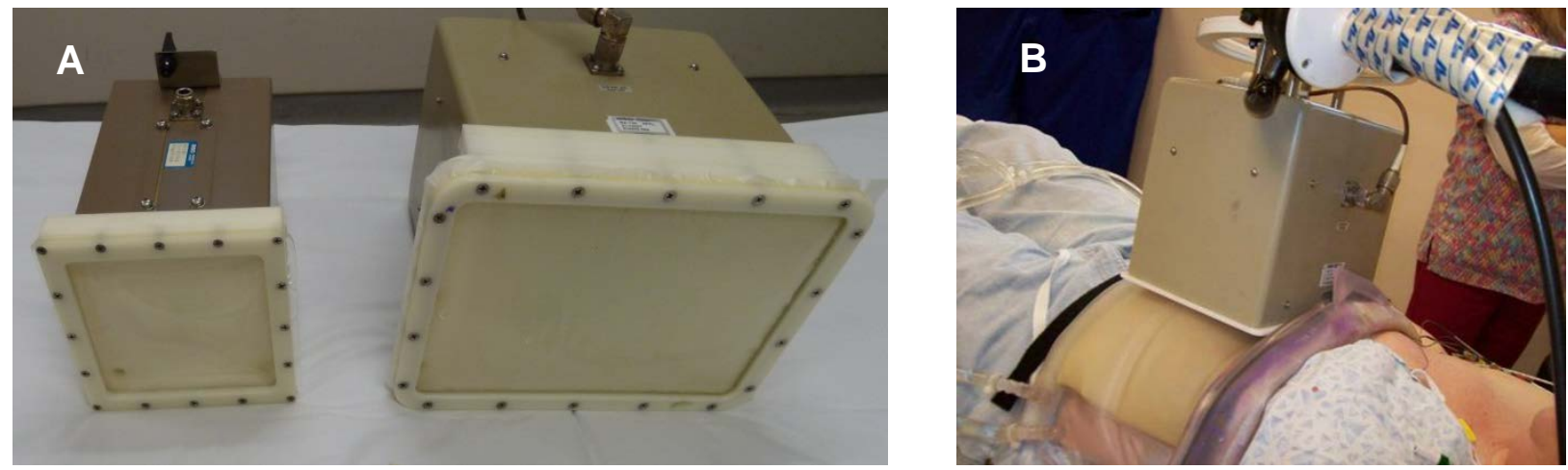

Figure 2 - FDA approved waveguide applicators available for superficial hyperthermia treatments in USA. A) MA-100 (left) and MA-120 (right) applicators with BSD rigid frame water coupling bolus (Pyrexar Medical - Salt Lake City UT); B) MA-120 applicator over custom conformal waterbolus which couples to widespread chestwall recurrent disease.

\subsection{Waterbolus coupling of waveguide to tissue}

In order to couple microwaves to larger areas of convex curvature, flexible (floppy bag) conformal boluses may be fabricated from readily available components to accommodate unique patient treatment configurations. The basic components of our conformal waterbolus bags are: i) ES-3000 10 mil PVC (Solvay Draka - City of Commerce CA); ii) 1/2” Dry Fast Foam (Foam N' More Inc - Clawson MI); and iii) polypropylene tee, quick connects, and tygon tubing (US Plastics Corp - Lima OH). Bags are easily fabricated to the desired dimensions by sealing the outer edges of double layer PVC fabric with a commercially available heat sealer (Sealersales - Northridge CA). A minimum thickness of the floppy bag compartment is maintained with a piece of porous foam with $1.3 \mathrm{~cm}$ thickness. Circulation of temperature controlled deionized water at flow rates of $>2 \mathrm{l} / \mathrm{min}$ is critical to maintain uniform cooling of the skin surface. As bolus bags increase in size, the distribution of water flow within the bolus becomes increasingly important. In 2011, the single input-single output (SISO) bolus configuration was introduced, which included Tygon tubes perforated with holes approximately $1 \mathrm{~cm}$ apart along the two sides of the bolus. ${ }^{20}$ However, this configuration works well only for small boluses since temperature varies significantly $\left(>2^{\circ} \mathrm{C}\right)$ in larger boluses as required for the MA-120 applicator. ${ }^{20}$ Dual input-dual output (DIDO) water boluses have been described previously which provide highly uniform distribution of water flow through much larger conformal water boluses but suffer from the added weight and impracticality of having two Tygon supply tubes to each side of bolus. ${ }^{21}$ In this effort, we developed a modified SISO bolus with a center feed design that distributes water flow uniformly across a moderately large bolus sufficient for the MA-120 waveguide applicator. These three bolus configurations are shown in Figure 3.
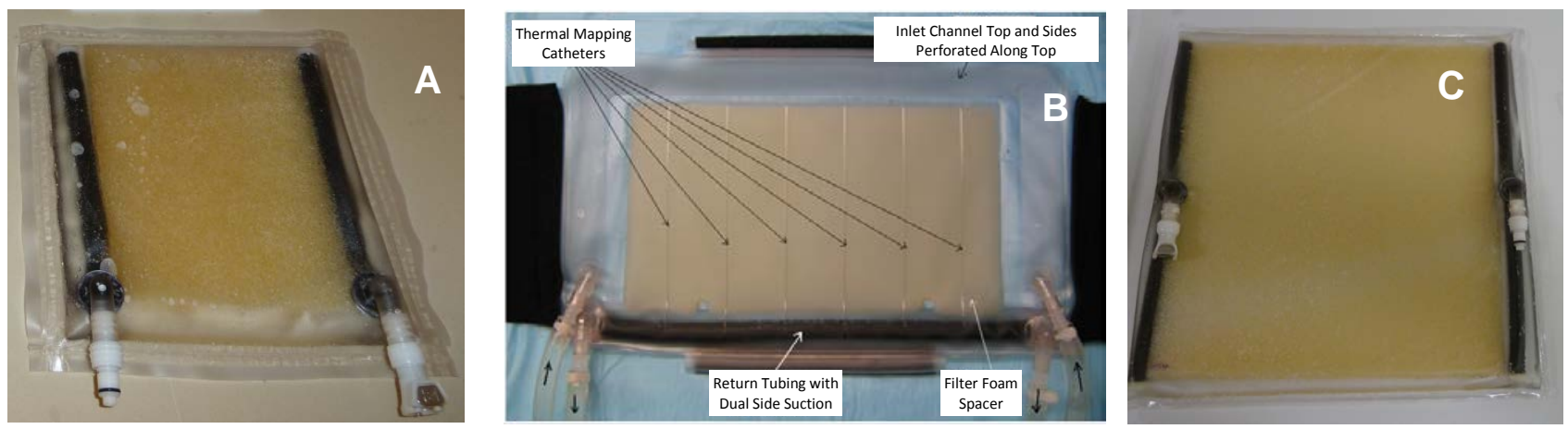

Figure 3 - A) Single input-single output (SISO) water bolus ${ }^{20}$ for coupling small microwave applicators such as MA-100; B) Dual input-dual output (DIDO) conformal waterbolus ${ }^{21}$ for uniform cooling of large treatment areas; C) Center-Fed SISO waterbolus designed for uniform flow distribution and coupling large waveguide applicators such as the MA-120. 


\subsection{Multiphysics computational model}

Microwave waveguide applicator model

The current effort focuses on treatment planning for the MA-120 waveguide applicator driven at $915 \mathrm{MHz}$, as available from Pyrexar Medical (Salt Lake City, UT). The waveguide dimensions are $17.4 \times 23.6 \times 19.6 \mathrm{~cm}^{3}$ and the computer-aided design (CAD) model is presented in Figure 4. The waveguide has an interior structure consisting of two lateral chambers filled with a dielectric powder $\left(\varepsilon_{r}=3, \sigma=1.5 \times 10^{-4} \mathrm{~S} / \mathrm{m}\right)$, two coaxial feeds, and two crossing metal blades that can be rotated mechanically during treatment to effect impedance matching of the waveguide to the tissue load. The dielectric chambers are supported by $6 \mathrm{~mm}$ thick Plexiglass walls and the waveguide aperture is covered with a $4 \mathrm{~mm}$ thick Delrin slab.
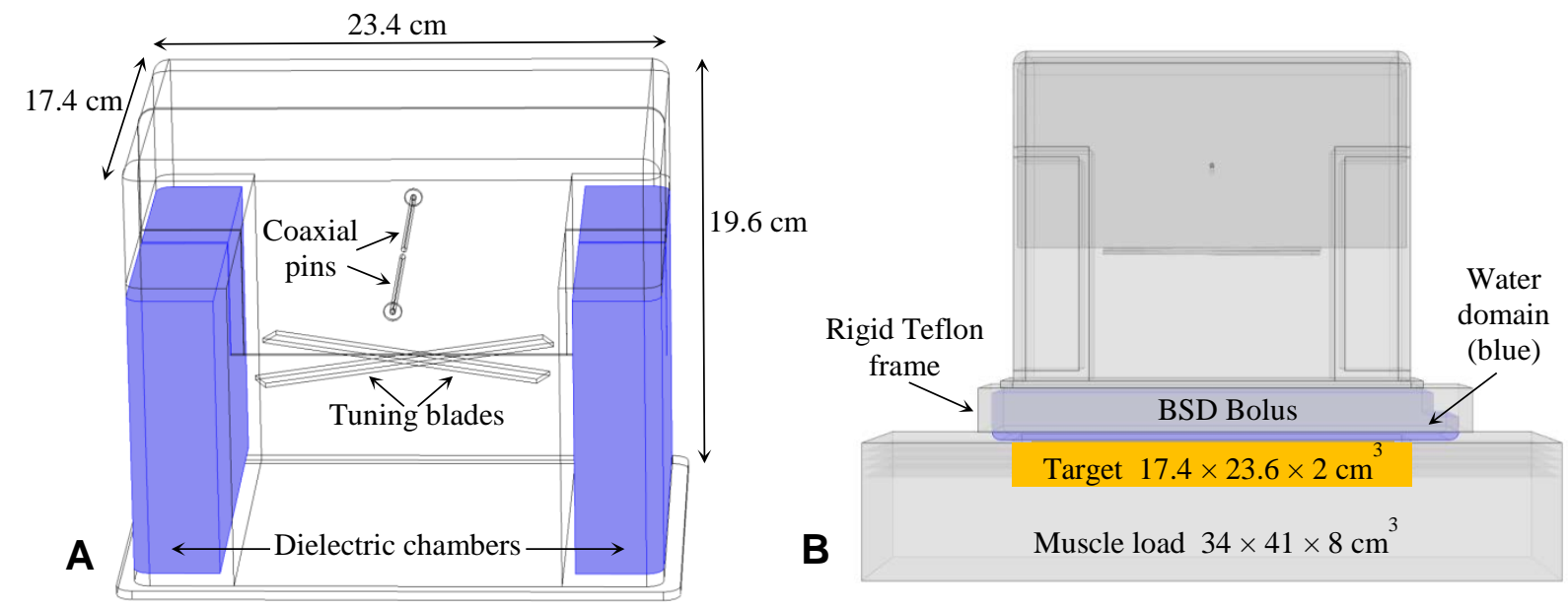

Figure 4 - Computational model: A) CAD model of the MA-120 waveguide with internal dielectric compartments and crossing tuning blades; and B) CAD model of the MA-120 applicator coupled to homogenous muscle tissue load with 2 $\mathrm{cm}$ target (orange) under rigid frame waterbolus. The bolus was filled with deionized water so that it extends $5 \mathrm{~mm}$ below the frame, making $2.8 \mathrm{~cm}$ total water thickness from waveguide applicator front face to phantom tissue surface.

\section{Experimental validation of SAR modeling}

Power deposition patterns of the MA-120 waveguide applicator were measured with a $6 \mathrm{~mm}$ diameter three-axis electric field probe (Model 8021B SAR Probe - Narda Corp, Hauppauge NY) using $1 \mathrm{~mm}$ step size raster scanning in a large tank containing liquid muscle-mimicking phantom. The probe provided an output signal directly proportional to total electric field squared $\left|E_{x, y, z}\right|^{2}$ which is proportional to specific absorption rate as in SAR $=\sigma E^{2} / 2 \rho$, where $\sigma$ is the electrical conductivity and $\rho$ the density of liquid phantom, respectively. The muscle-mimicking phantom is a mixture of $70 \%$ ethylene glycol, $28 \%$ distilled water, and $2 \%$ non-iodized table salt as needed to simulate the dielectric properties of muscle at $915 \mathrm{MHz}$ (see tissue properties in Table I). Details of the scan tank setup and procedures for SAR determination have been reported previously. ${ }^{22,23}$

Several treatment configurations of the MA-120 applicator were measured experimentally and later the same physical setups were modeled with the electromagnetic simulation software COMSOL Multiphysics (COMSOL Inc. - Burlington MA), which uses the finite element method. Simulations were compared directly to the measured SAR distributions to establish validity of our electromagnetic modeling. Three coupling configurations were analyzed between the MA-120 applicator and the phantom load: i) direct contact; ii) $3 \mathrm{~cm}$ air gap; and iii) rigid frame waterbolus (BSD bolus) filled with deionized water so the silicone fabric protruded $5 \mathrm{~mm}(2.8 \mathrm{~cm}$ total) beyond the waterbolus frame (Figure 4B). A blade rotation of $\alpha_{\text {blades }}=65^{\circ}$ was used for both experimental and simulation scenarios. The applicator was directed into the scan tank through a thin Mylar window and supported on the exterior of the tank to maintain perpendicular orientation to the liquid muscle load and intimate contact with the Mylar (for configurations ii and iii). 


\section{Tissue models with water bolus coupling}

Besides the tissue models used for validation, two more tissue models were analyzed - both with waterbolus coupling. The first was used for thermal characterization purposes and consisted of homogeneous muscle with $34 \times 41 \times 8 \mathrm{~cm}^{3}$ dimensions. Configurations tested in this study included 3 bolus shapes: a $1.3 \mathrm{~cm}$ thick slab bolus with varying lateral dimensions relative to the $17.4 \times 23.6 \mathrm{~cm}^{2}$ waveguide aperture; a wedge shaped bolus varying from $1.3 \mathrm{~cm}$ to $2.6 \mathrm{~cm}$ thick across the aperture face; and a conformal bolus that was $2.6 \mathrm{~cm}$ thick around the waveguide perimeter and $1.3 \mathrm{~cm}$ centrally. In the last two cases, the waterbolus extended laterally $2 \mathrm{~cm}$ beyond the waveguide aperture. For all three phantom studies, a $2 \mathrm{~cm}$ thick muscle tissue target was considered for temperature-volume histogram analysis with lateral dimensions matching the waveguide aperture (Figure 4B). The second tissue model was designed to mimic patient anatomy more closely. It consisted of a contoured multi-layer domain with $1.5 \mathrm{~mm}$ skin, $1.5 \mathrm{~cm}$ fat, $1 \mathrm{~cm}$ muscle with interspersed ribs, and $8 \mathrm{~cm}$ lung. The rib cross section was elliptical in shape $\left(7 \times 25 \mathrm{~cm}^{2}\right)$. The $13.4 \times 19.6 \times 1.65$ $\mathrm{cm}^{3}$ tumor target was centered within the waveguide and surrounded by skin and fat tissues, not invading the muscle layer. The electrical, thermal and physiological properties for all tissue regions are given in Table I.

\section{Bioheat transfer model}

The E-field and temperature were calculated in COMSOL to solve the combined bioheat transfer equation and Maxwell's equations. ${ }^{24}$ The bioheat equation consists of an extended version of the classic heat equation with a heat sink due to blood perfusion $\left(\omega_{b}\right)$, an internal heat source due to metabolism $\left(Q_{m}\right)$ and an external heat source due to absorption of microwave energy derived from the applicator $(\rho S A R)$. The cooling bolus was embodied in a Robin boundary condition with $T_{\text {bolus }}=42^{\circ} \mathrm{C}$ and $h_{\text {bolus }}=85 \mathrm{~W} / \mathrm{m}^{2} / \mathrm{K}^{24}$. For the top and lateral surfaces, a similar boundary condition was imposed for air cooling with $T_{\text {air }}=25^{\circ} \mathrm{C}$ and $h_{\text {air }}=5 \mathrm{~W} / \mathrm{m}^{2} / \mathrm{K}$. At the bottom surface, we used $T_{\text {core }}=$ $37^{\circ} \mathrm{C}$ and $h_{\text {core }}=200 \mathrm{~W} / \mathrm{m}^{2} / \mathrm{K}$. To accommodate thermoregulation, we incorporated a temperature dependent blood perfusion model because blood perfusion is a dynamic heat sink that varies with temperature during hyperthermia treatments ${ }^{25,26}$. To account for this thermoregulatory effect, a temperature-dependent scaling function was included:

$$
F(T)=\left\{\begin{array}{rr}
1+\omega_{1} \exp \left(-\frac{\left(T-T_{c r}\right)^{2}}{s}\right), & T \leq T_{c r} \\
1+\omega_{1} & , T>T_{c r}
\end{array}\right.
$$

where $\omega_{1}$ and $s$ are curve fitting parameters derived from experimental data; and $T_{c r}$ is a critical temperature that is tissue-specific (Table I). Finally, a parametric optimization scheme was implemented for the antenna input power $(P)$ in order to achive a therapeutic temperature in the tumor target with an upper limit anywhere in tissue of $45^{\circ} \mathrm{C}$.

Table 1: Electrical, thermal, and physiological properties of human tissues used for phantom models, with F(T) given by equation 1.

\begin{tabular}{|c|c|c|c|c|c|c|c|c|c|c|}
\hline Tissue & $\underset{\left.\mathrm{g} / \mathrm{m}^{3}\right)}{\rho}$ & $\begin{array}{c}C_{p} \\
(\mathrm{~J} / \mathrm{kg} / \mathrm{K})\end{array}$ & $\begin{array}{c}k \\
(\mathrm{~W} / \mathbf{m} / \mathbf{K})\end{array}$ & $\begin{array}{c}\omega_{b} \\
\left(\mathrm{~kg} / \mathbf{s} / \mathbf{m}^{3}\right)\end{array}$ & $\begin{array}{c}Q_{m} \\
\left(\mathrm{~W} / \mathrm{m}^{3}\right)\end{array}$ & $\begin{array}{c}s \\
\left({ }^{\circ} C^{2}\right)\end{array}$ & $\omega_{1}$ & $\begin{array}{c}T_{c r} \\
\left({ }^{\circ} \mathbf{C}\right)\end{array}$ & $\varepsilon_{r}$ & $\begin{array}{c}\sigma \\
(\mathrm{S} / \mathrm{m})\end{array}$ \\
\hline Skin (wet) & $1109^{27}$ & $3391^{27}$ & $0.37^{27}$ & $0.97 \times F(T)^{27}$ & $1827^{27}$ & $10^{28}$ & $9.2^{28}$ & $44^{28}$ & $46.0^{29}$ & $0.85^{29}$ \\
\hline Fat & $911^{27}$ & $2348^{27}$ & $0.21^{27}$ & $0.52 \times F(T)^{27}$ & $461^{27}$ & $12^{28}$ & $1.0^{28}$ & $45^{28}$ & $5.5^{29}$ & $0.05^{29}$ \\
\hline Muscle & $1090^{27}$ & $3421^{27}$ & $0.49^{27}$ & $0.75 \times F(T)^{27}$ & $1052^{27}$ & $12^{28}$ & $4.0^{30}$ & $45^{28}$ & $55.0^{29}$ & $0.95^{29}$ \\
\hline Lung & $722^{27}$ & $3886^{27}$ & $0.39^{27}$ & $5.06^{27}$ & $4483^{27}$ & - & - & - & $36.7^{29}$ & $0.66^{29}$ \\
\hline Rib & $1543^{27}$ & $1793^{27}$ & $0.32^{27}$ & $0.48^{27}$ & $421^{27}$ & - & - & - & $16.6^{29}$ & $0.24^{29}$ \\
\hline Muscle phantom & 1097 & 3083 & 0.31 & - & - & - & - & - & $46^{\mathrm{a}}$ & $1.26^{\mathrm{a}}$ \\
\hline De-ionized water & 992 & 4176 & 0.63 & - & - & - & - & - & $79^{\mathrm{a}}$ & $0.18^{\mathrm{a}}$ \\
\hline
\end{tabular}

\footnotetext{
a measured.
} 


\section{RESULTS}

\subsection{Temperature uniformity across the waterbolus}

Water boluses were constructed in several sizes to couple the MA-120 waveguide applicator to tissue sites overlying different parts of the anatomy. The time response and uniformity of temperature across the bolus were verified with measurements of bolus/tissue interface temperature during step changes of water temperature circulated through the bolus, as seen in Figure 5. Following initial transient $<2.0^{\circ} \mathrm{C}$ differences between inlet and outlet temperature attained during the $\sim 5^{\circ} \mathrm{C}$ step changes in circulating water temperature, 12 sensors spaced widely apart on the bolus (Figure 5 right) recorded almost identical temperatures within $0.2-0.4^{\circ} \mathrm{C}$ of each other within about 3 minutes of changing the water bath source temperature. The water circulation rate was $3.8 \mathrm{l} / \mathrm{min}$ in the Tygon inlet and outlet tubing. This bolus created a large region of nearly homogeneous temperature that extended $>5 \mathrm{~cm}$ outside the perimeter of the MA-120 applicator. This provided uniform cooling and temperature control of the skin surface as well as a continuous high dielectric $\left(\varepsilon_{r}=79\right)$ interface between flat waveguide aperture and contoured tissue surface.
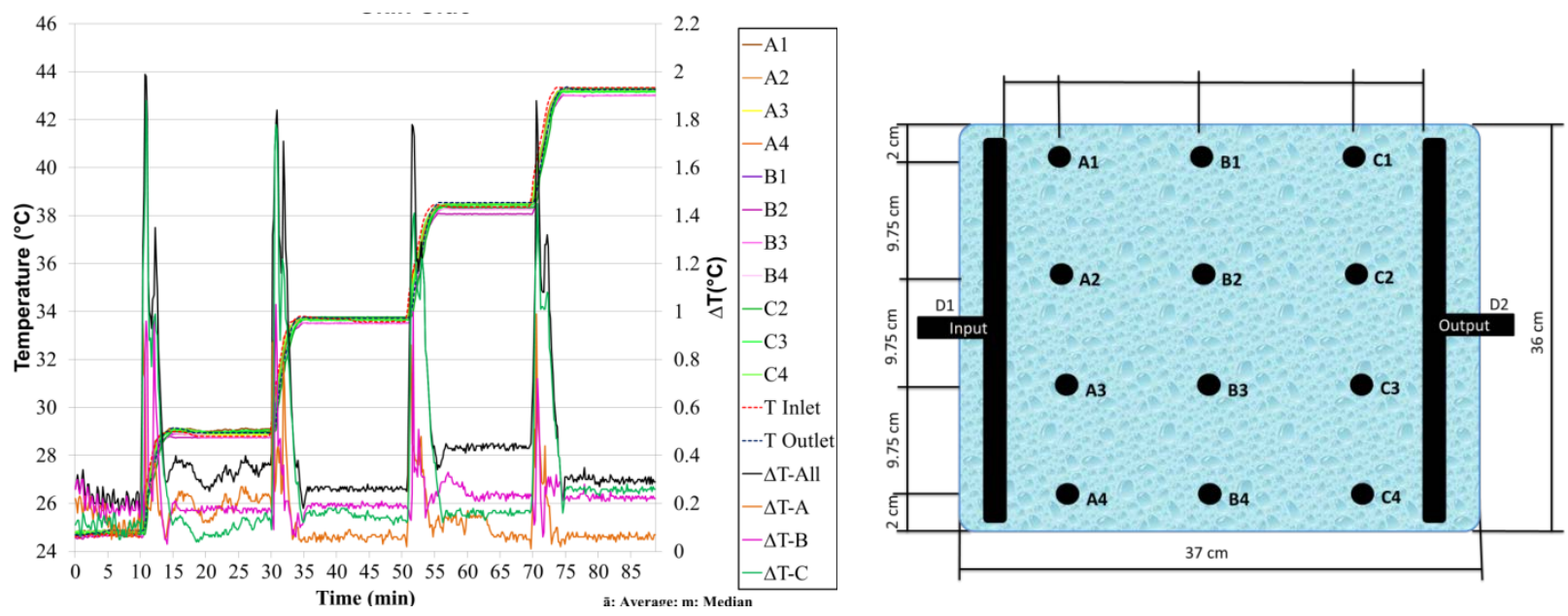

Figure 5 - Temperature recording at 14 locations on the skin interface side of a $36 \times 37 \times 1.3 \mathrm{~cm}^{3}$ center-fed single inputsingle output waterbolus during four $\sim 5^{\circ} \mathrm{C}$ step increases in circulating water temperature. Note the large $\sim 2^{\circ} \mathrm{C}$ transient difference in inlet and outlet temperatures lasting $<3 \mathrm{~min}$ and then stable within $0.2-0.4^{\circ} \mathrm{C}$ at all locations on the bolus.

\subsection{Validation of computational model with matching experimental measurements}

The experimental SAR results were measured in homogeneous muscle phantom for three coupling mediums: direct contact (Figure 6), $3 \mathrm{~cm}$ air gap (Figure 7), and BSD bolus (Figure 8). Simulations of these three coupling configurations are shown for the $5 \mathrm{~mm}, 10 \mathrm{~mm}$, and $15 \mathrm{~mm}$ deep planes. SAR countours are displayed every $5 \%$ (gray), and highlighted at 95\% (purple), 75\% (yellow), 50\% (red), and 25\% (green) of the peak SAR in the $5 \mathrm{~mm}$ deep plane. The rectangular waveguide aperture is highlighted in blue. For the direct contact case of Figure 6, the experimental $\mathrm{SAR}_{50}$ countour bulges at the corners, whereas the simulation did not predict such pattern. This might be related to imperfect stretching of the thin Mylar window at the corners while pressing the applicator flat against the slightly bulging Mylar separation to liquid muscle inside the scan tank. For the direct contact and $3 \mathrm{~cm}$ air coupling cases, the 15 mm plane shows an $\mathrm{SAR}_{50}$ countour with slightly reduced area as compared to the experimental measurements. This mismatch might be related to the experimental SAR scanning resolution that is 1-2 mm. Despite these minor diffrences, the overall shapes and countor areas present excellent agreement between measured and simulated SAR patterns, confirming the validity of this theoretical model for further studies of MA-120 heating patterns.

Figure 8 shows the effect of adding water as a coupling medium. The SAR pattern spreads across the waveguide aperture, indicating a preferred coupling medium for large tumor targets when compared with direct contact and air coupling. Providing exactly $5 \mathrm{~mm}$ water thickness protruding from the BSD frame to contact the slightly bulging Mylar window was challenging experimentally. Despite slight quantitative differences, the measured and simulated SAR patterns show good overall agreement, correctly predicting locations of SAR peaks and nulls across the applicator at all depths. 


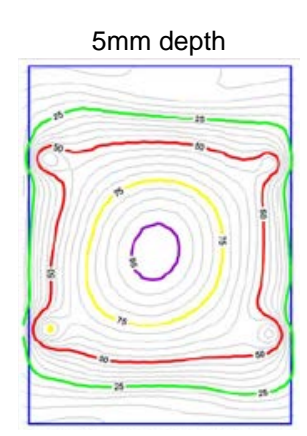

Experimental SAR Patterns
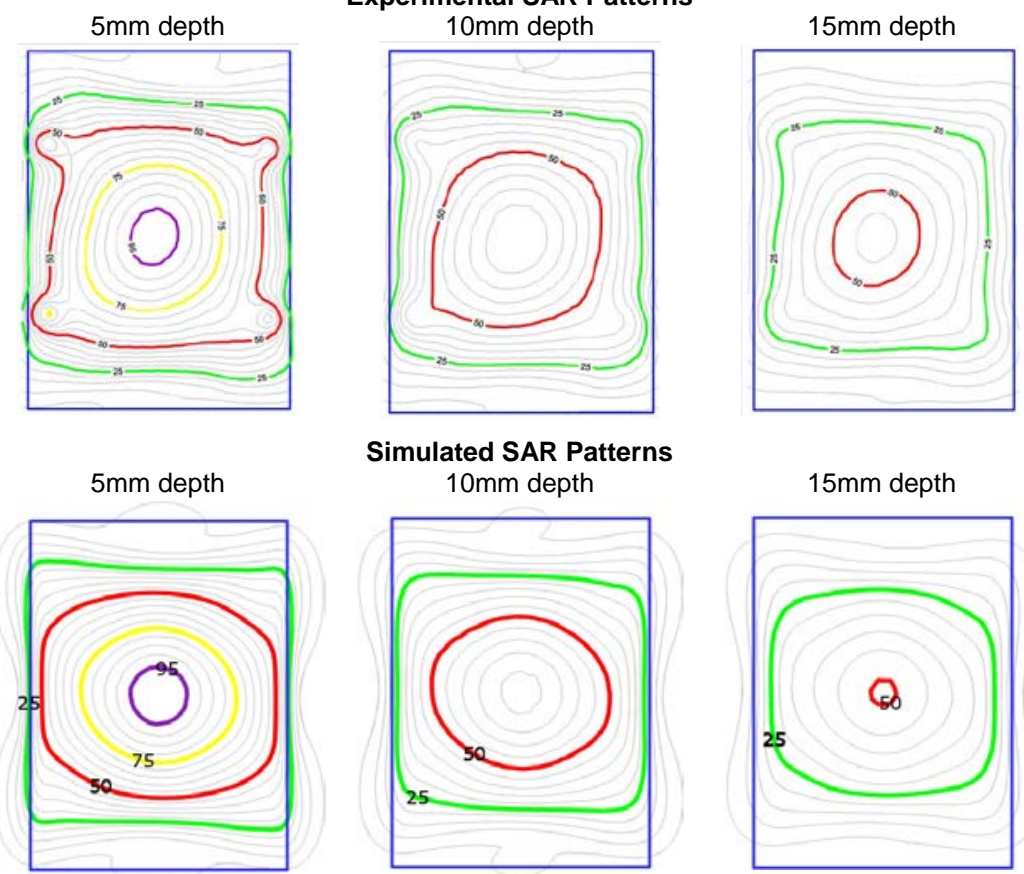

Simulated SAR Patterns $10 \mathrm{~mm}$ depth

$15 \mathrm{~mm}$ depth
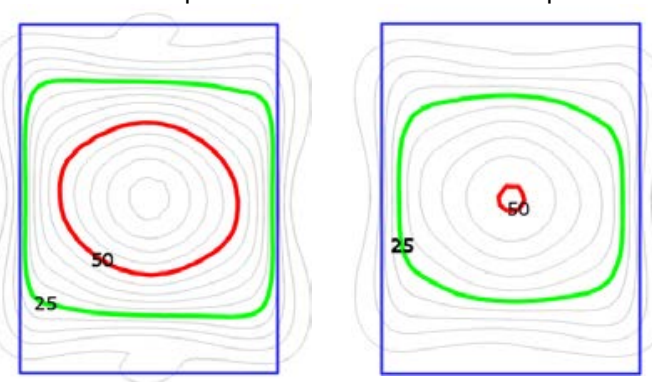

Figure 6 - SAR measurements 5 mm deep in muscle phantom from MA-120 applicator coupled with direct contact to phantom. Blue frame corresponds to waveguide perimeter and normalization was at $5 \mathrm{~mm}$ depth.

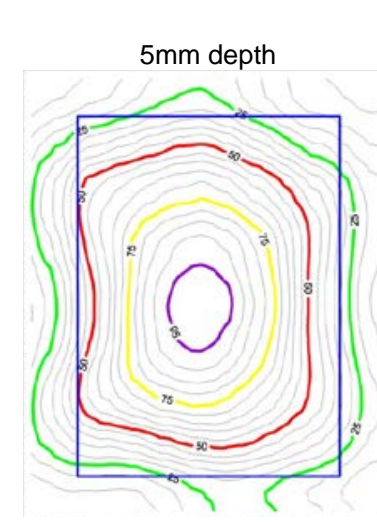

\section{Experimental SAR Patterns $10 \mathrm{~mm}$ depth}

$15 \mathrm{~mm}$ depth
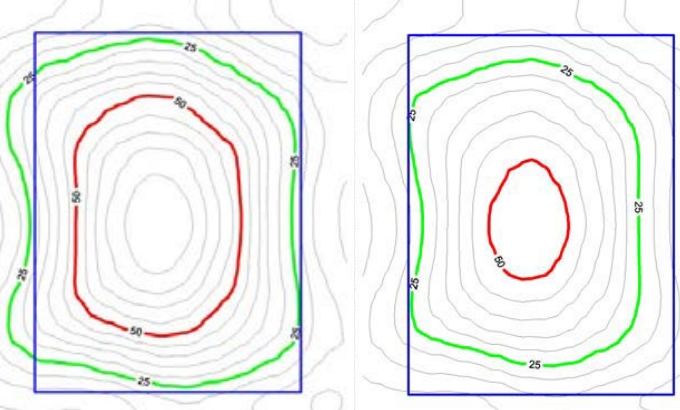

$5 \mathrm{~mm}$ depth

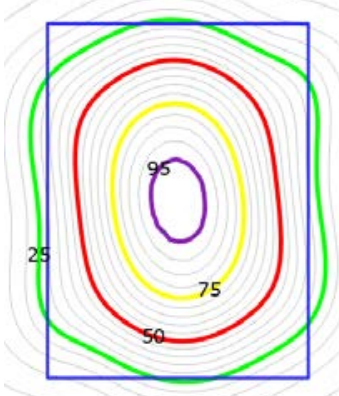

Simulated SAR Patterns $10 \mathrm{~mm}$ depth

$15 \mathrm{~mm}$ depth
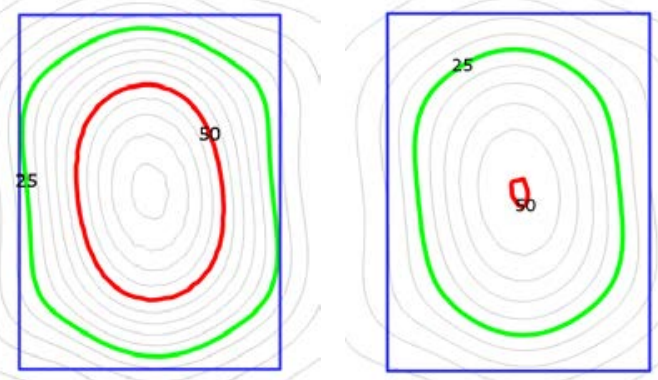

Figure 7 - SAR measurements 5 mm deep in muscle phantom from MA-120 applicator coupled with to phantom with 3 $\mathrm{cm}$ air gap. Blue frame corresponds to waveguide perimeter $\left(17.4 \times 23.6 \mathrm{~cm}^{2}\right)$ and normalization was at $5 \mathrm{~mm}$ depth. 
Experimental SAR Patterns

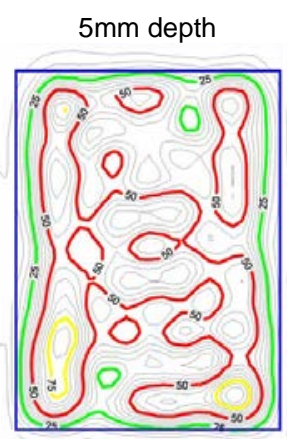

$10 \mathrm{~mm}$ depth

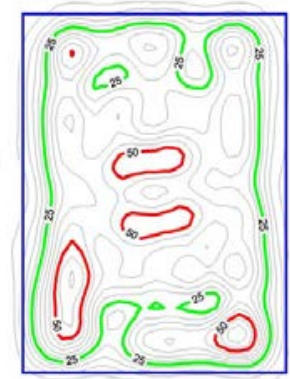

Simulated SAR Patterns $10 \mathrm{~mm}$ depth
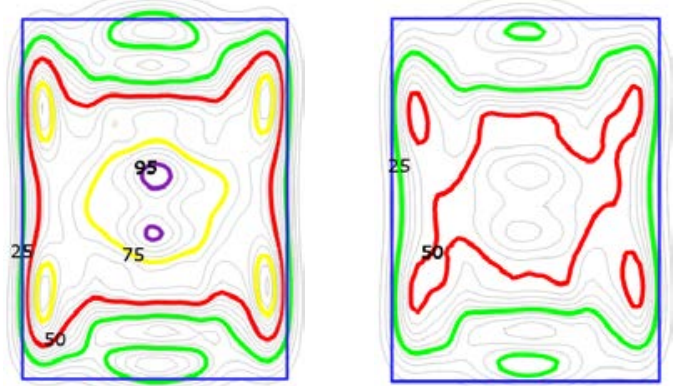

$15 \mathrm{~mm}$ depth

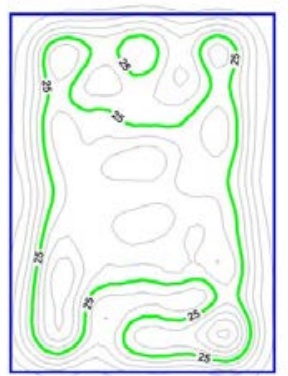

$15 \mathrm{~mm}$ depth

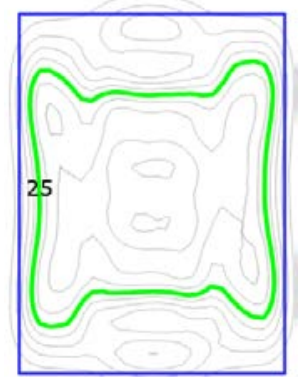

Figure 8 - SAR measurements 5 mm deep in muscle phantom from MA-120 applicator coupled with direct contact to phantom. Blue frame corresponds to waveguide perimeter and normalization was at $5 \mathrm{~mm}$ depth. Note close correlation of simulations to the experimental measurements.

\subsection{Effect of varying MA-120 impedance matching tuning blades}

The MA-120 applicator includes a tuning knob to adjust the angle of rotation $\left(\alpha_{\text {blades }}\right)$ of the two metal bars. This angle may be adjusted from parallel to crossing at any angle up to almost perpendicular 90 degree orientation. The effect on SAR pattern is shown in the simulations of Figure 9 which show a distinct expansion of the SAR laterally as the angle of rotation increases towards perpendicular orientation.
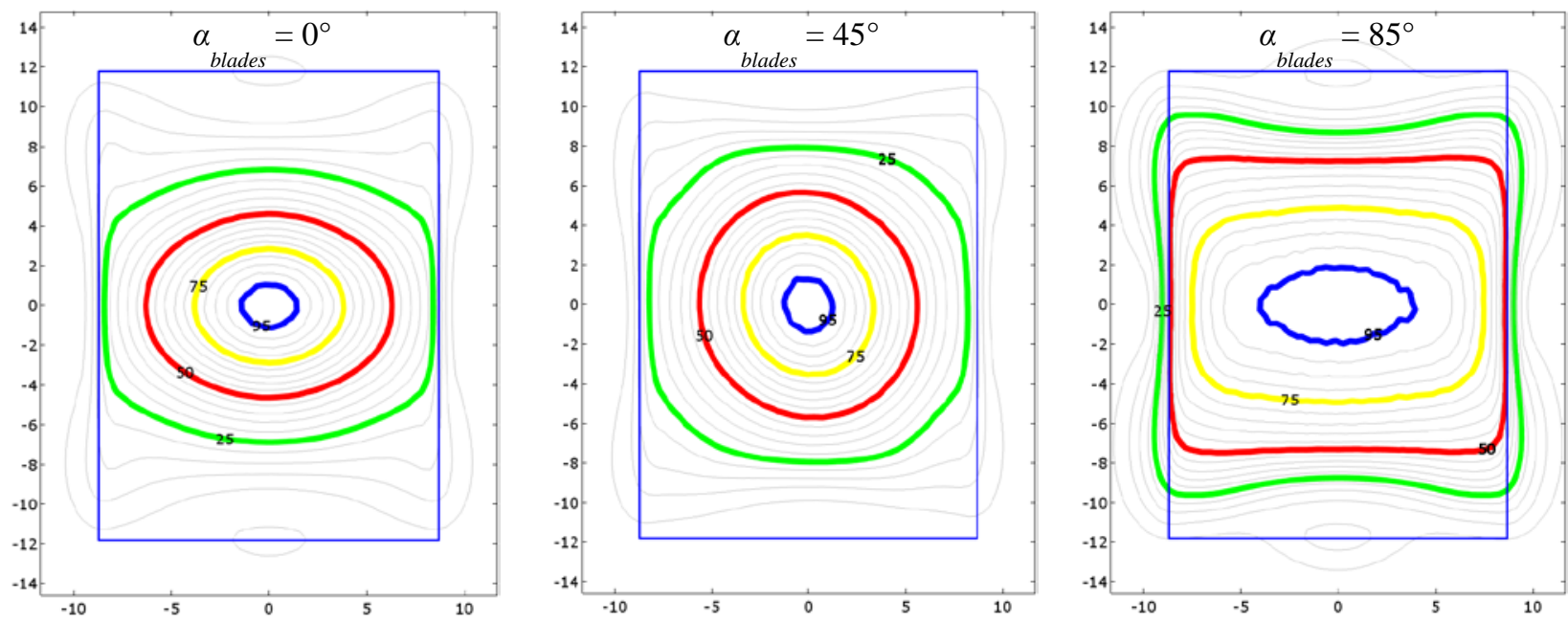

Figure 9 - SAR simulations $5 \mathrm{~mm}$ deep in homogeneous muscle for three different rotations of the MA-120 impedance matching tuning blades. Note the elongation of heating pattern across the short side of applicator for widely separated blades in a "+" configuration (right), as compared to parallel (left) or " $\mathrm{X}$ " (center) tuning blade configurations. The blue outline delineates the $17.4 \times 23.6 \mathrm{~cm}^{2}$ waveguide aperture. 


\subsection{Effect of varying lateral dimensions of bolus}

The effect on SAR of varying waterbolus lateral dimensions relative to applicator and tissue load is demonstrated in Figure 10. Tissue heating patterns are shown for cases with the $1.3 \mathrm{~cm}$ thick bolus extending $2 \mathrm{~cm}$ and $1 \mathrm{~cm}$ inside the waveguide aperture, aligned with the aperture, and $1 \mathrm{~cm}, 2 \mathrm{~cm}$, and $3.5 \mathrm{~cm}$ outside the perimeter of MA-120 aperture. The SAR pattern is shown for a plane $5 \mathrm{~mm}$ deep in tissue, cutting through a homogenous muscle load with a $17.4 \times$ $23.6 \times 2 \mathrm{~cm}^{3}$ muscle target region aligned under the waveguide.

\section{Aperture - 2cm (Size S) \\ Aperture $-1 \mathrm{~cm}$}

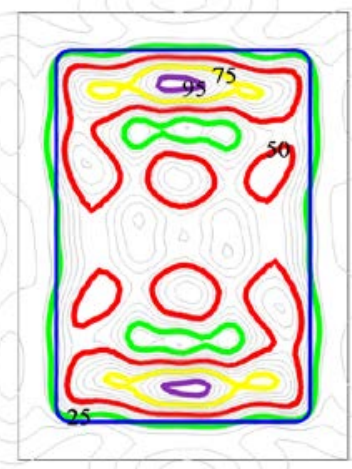

Aperture $+1 \mathrm{~cm}$

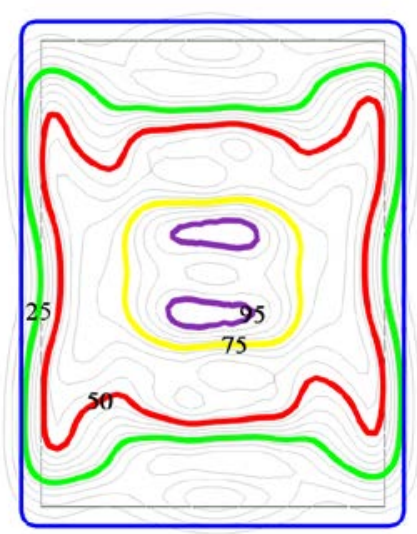

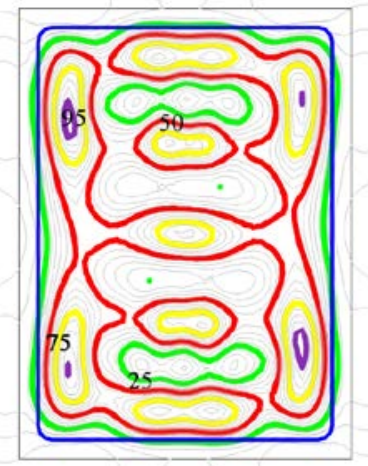

Aperture $+2 \mathrm{~cm}($ Size L)

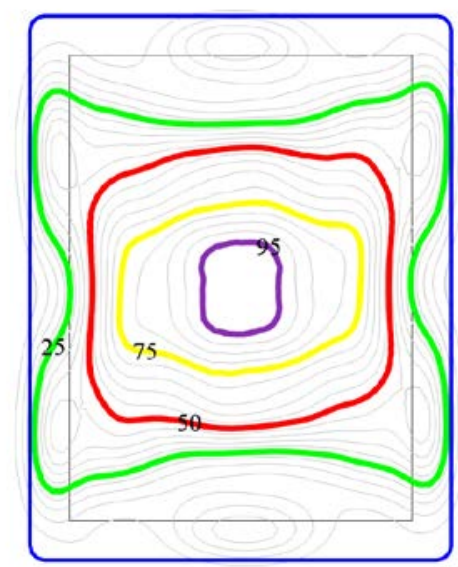

Aperture Edge (Size M)

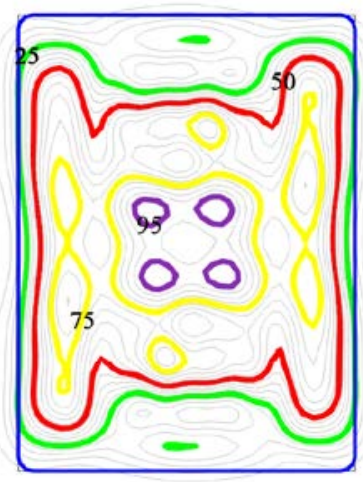

Aperture $+3.5 \mathrm{~cm}$ (Size $\mathrm{XL}$ )

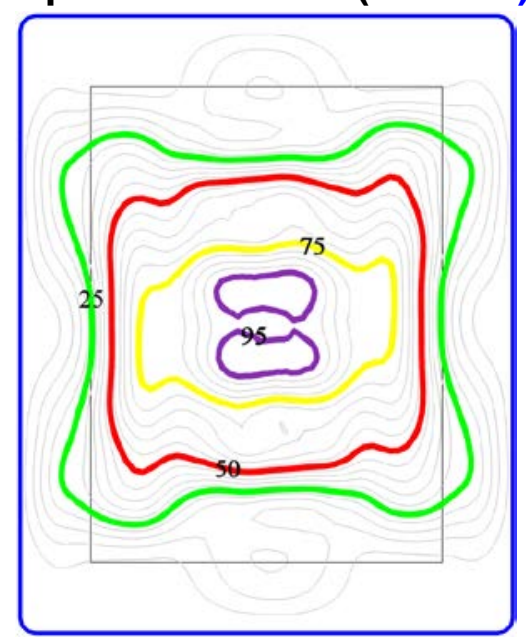

Figure 10 - Numerical simulations showing the effect on SAR pattern of varying the lateral dimensions of a $1.3 \mathrm{~cm}$ thick waterbolus coupling an MA-120 applicator to homogenous muscle tissue load. Water bolus size is indicated with blue outline and the $17.4 \times 23.6 \mathrm{~cm}^{2} \mathrm{MA}-120$ aperture in black.

The SAR patterns of Figure $\mathbf{1 0}$ were converted to temperature distributions expected from those power deposition patterns in muscle tissue assuming temperature dependent blood perfusion properties given in Table 1 . The waterbolus had an input/output flow rate of $3.4 \mathrm{l} / \mathrm{min}$ of $42^{\circ} \mathrm{C}$ water yielding a heat transfer coefficient of $85 \mathrm{~W} / \mathrm{m}^{2} / \mathrm{K}$ through the PVC fabric to tissue. ${ }^{24}$ Microwave power was adjusted to attain $45^{\circ} \mathrm{C}$ in each simulation. Figure 11 shows 41,42 and $43^{\circ} \mathrm{C}$ iso-temperature contours in the plane $5 \mathrm{~mm}$ deep in perfused muscle tissue. Clearly the lateral dimensions of waterbolus affect the heating patterns of the MA-120 applicator by moving the heat peaks around under the aperture. However, as shown in Figure 12 the percentage of target tissue under the applicator is quite similar for all but the impractically small bolus (size S) that does not cover the entire waveguide aperture. 

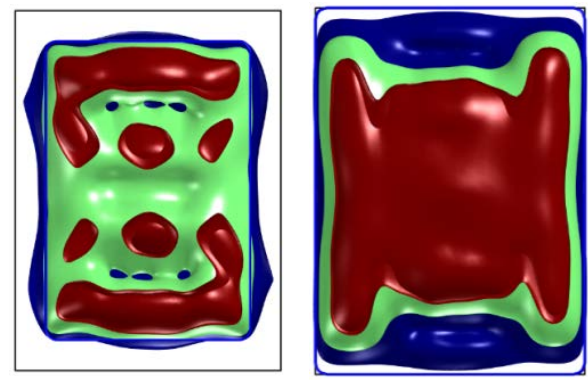

Bolus S, $\mathrm{P}=255 \mathrm{~W}$

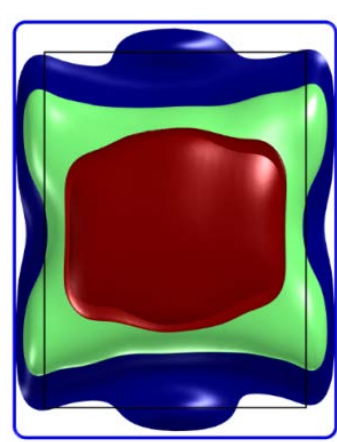

Bolus L, $\mathrm{P}=230 \mathrm{~W}$
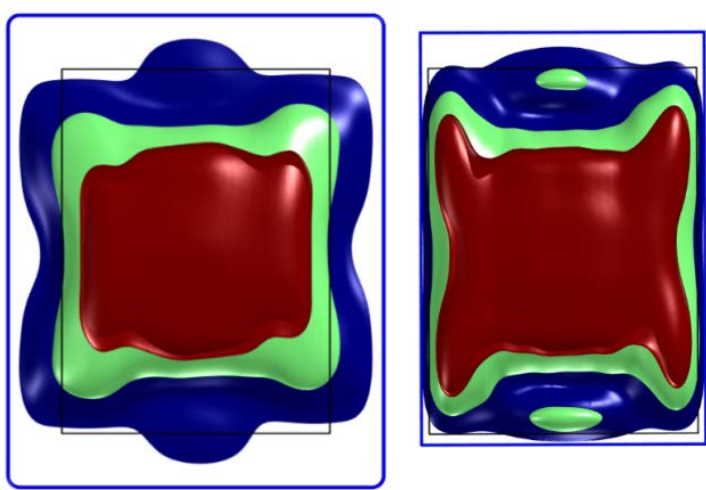

Bolus XL, $\mathrm{P}=230 \mathrm{~W}$
BSD Bolus, $\mathrm{P}=195 \mathrm{~W}$

Figure 11 - Top view of iso-temperature contour simulations in a homogenous muscle under a $1.3 \mathrm{~cm}$ thick water bolus of various sizes coupling an MA- 120 applicator. Blue contour is $41^{\circ} \mathrm{C}$, green is $42^{\circ} \mathrm{C}$, and red is $43^{\circ} \mathrm{C}$. Maximum temperature in each case is $45^{\circ} \mathrm{C}$ anywhere in tissue. $\mathrm{P}$ stands for antenna input power.

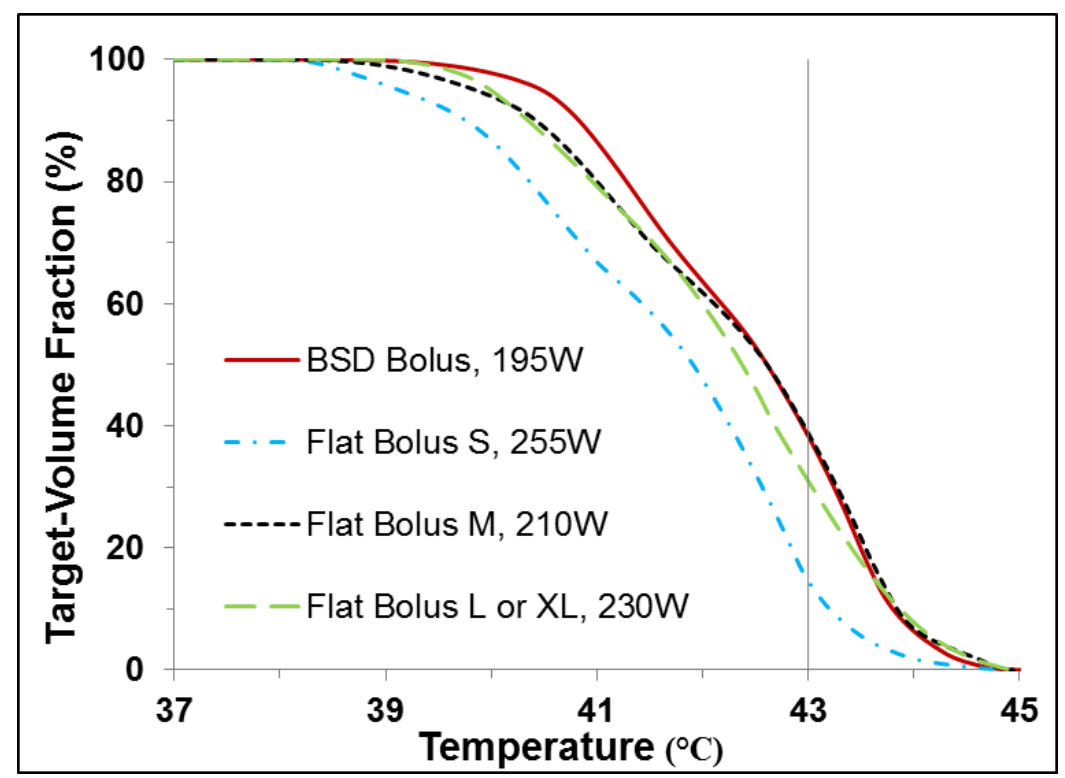

Figure 12 - Quantification of cumulative temperature-volume histograms for the different waterbolus configurations shown in Figure 11. Except for the impractically small bolus inside the waveguide aperture, very similar percentages of the target are heated with each bolus although heat peaks reach different areas of the target.

\subsection{Effect of variable thickness bolus}

Patient treatment setups are rarely a simple planar uniform thickness water layer overlying a predominantly homogenous tissue load. Generally, the waterbolus must accommodate an irregular, sloping, or contoured skin surface relative to the flat waveguide front face. Figure 13 shows SAR patterns $5 \mathrm{~mm}$ deep in muscle tissue for three simplified treatment setups. These three cases model: i) MA-120 applicator aimed perpendicularly into tissue through a planar $1.3 \mathrm{~cm}$ thick waterbolus; ii) MA-120 at an angle to tissue surface with wedge shaped waterbolus varying from 1.3 to $2.6 \mathrm{~cm}$ thick across the aperture; and iii) MA-120 aimed directly into a convex contoured surface such the center of the aperture is coupled through $1.3 \mathrm{~cm}$ water while the periphery of bolus is $2.6 \mathrm{~cm}$ thick. The SAR patterns stretch away from the center for thicker irregularly shaped waterboluses, but do not change patterns significantly. Although minor differences are evident, the quantitative temperature-volume histograms shown in Figure $\mathbf{1 4}$ for these three cases demonstrate that the effect of varying bolus configuration is relatively small for a homogenous muscle load. 


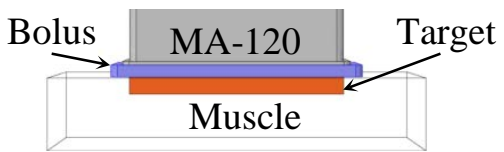

A

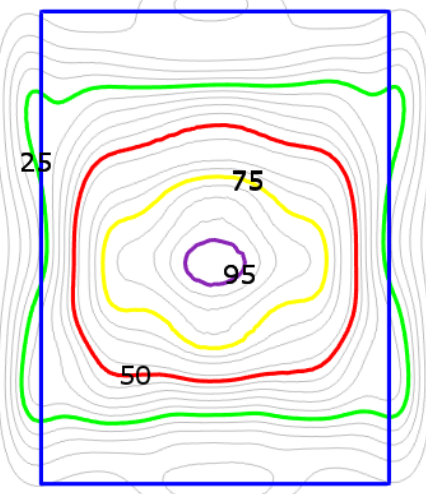

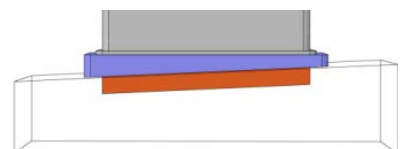

B

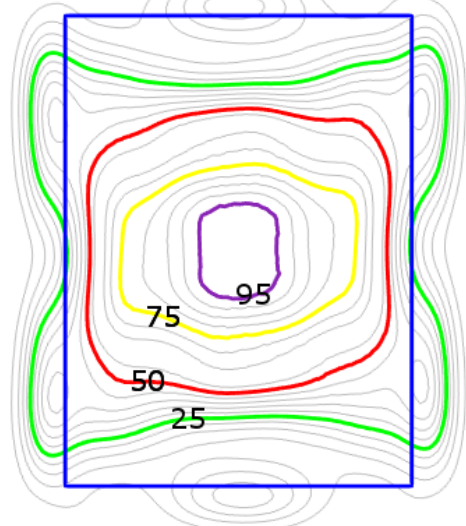

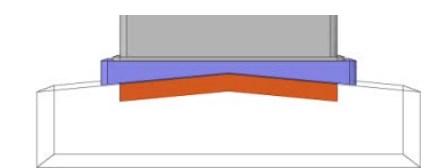

C

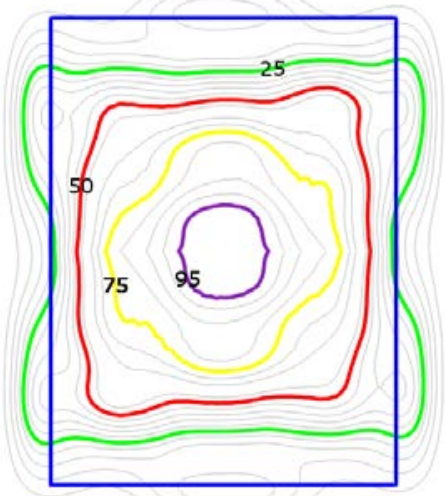

Figure 13 - Simulations of SAR patterns $5 \mathrm{~mm}$ deep in layered tissue with $17.4 \times 23.6 \times 2 \mathrm{~cm}^{3}$ tumor target (orange) in 8 cm deep muscle load under an MA-120 applicator coupled through: A) $1.3 \mathrm{~cm}$ constant thickness waterbolus; B) wedge shaped waterbolus from 1.3 - $2.6 \mathrm{~cm}$ thick; and C) conformal shape waterbolus with $1.3 \mathrm{~cm}$ thickness centrally increasing to $2.6 \mathrm{~cm}$ at the perimeter of bolus. Note relatively minor variation of SAR pattern with three different bolus configurations gives some flexibility of coupling without major impact on volume of effectively heated tissue.

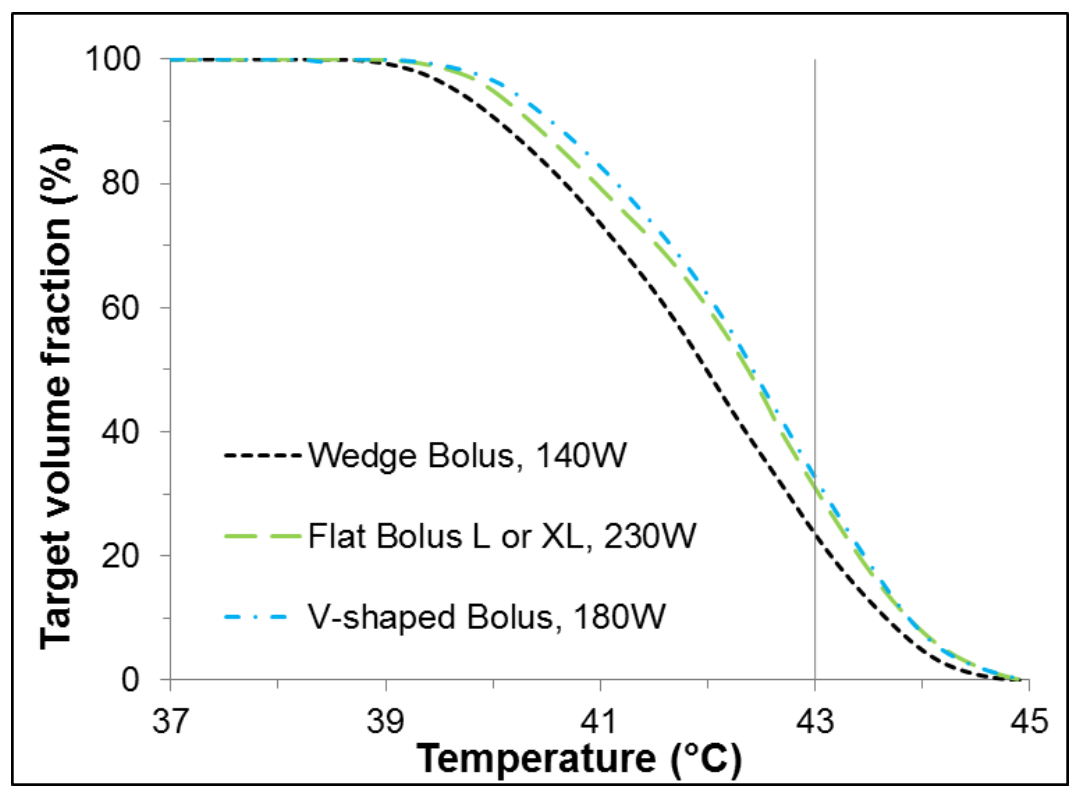

Figure 14 - Numerical simulation of cumulative temperature-volume histograms for the three water coupling bolus configurations shown in Figure 13 showing similar treatment volumes regardless of minor differences in heating patterns.

In clinical use of the MA-120 waveguide, there is usually a convex curvature to the skin surface and the underlying tissue load consists of layers of skin, fat, tumor, muscle, bone (e.g. ribs), and often underlying lung. Along with the irregular geometry, these tissues have considerably different dielectric and perfusion properties which affect the heating pattern. Tissue properties used in the simulations are given in Table 1 for each of these tissues. Figure $\mathbf{1 5}$ shows the 
thermal simulations in a human chestwall model for two very practical coupling bolus setups, with a conformal bolus that is pushed against the patient to form either a $6 \mathrm{~mm}$ or $13 \mathrm{~mm}$ thickness centrally while bulging to either 2.6 or 3.3 $\mathrm{cm}$ thick to fill the space between applicator and tissue around the antenna periphery. The "tumor" target extends from the skin surface to $1.65 \mathrm{~cm}$ depth and laterally out to $2 \mathrm{~cm}$ from the perimeter of waveguide $\left(13.4 \times 19.6 \times 1.65 \mathrm{~cm}^{3}\right)$, surrounded by normal skin $(1.5 \mathrm{~mm})$ and fat $(1.5 \mathrm{~cm})$. The $433 \mathrm{~cm}^{3}$ tumor volume is directly over a $1 \mathrm{~cm}$ layer of muscle that includes seven ribs (bone tissue) with $7 \times 25 \mathrm{~mm}^{2}$ elliptical cross section. The interior white $41^{\circ} \mathrm{C}$ contour line extends around the central three ribs for the 6-26 mm thick bolus and expands out to include 5 ribs with the 13-33 $\mathrm{mm}$ thick bolus. As seen in Figure 16, the 13-33 mm thick bolus significantly improves the percentage of the $433 \mathrm{~cm}^{3}$ target volume that is heated effectively above $41^{\circ} \mathrm{C}(18 \%), 42^{\circ} \mathrm{C}(34 \%), 43^{\circ} \mathrm{C}(32 \%)$, and $44^{\circ} \mathrm{C}(15 \%)$.
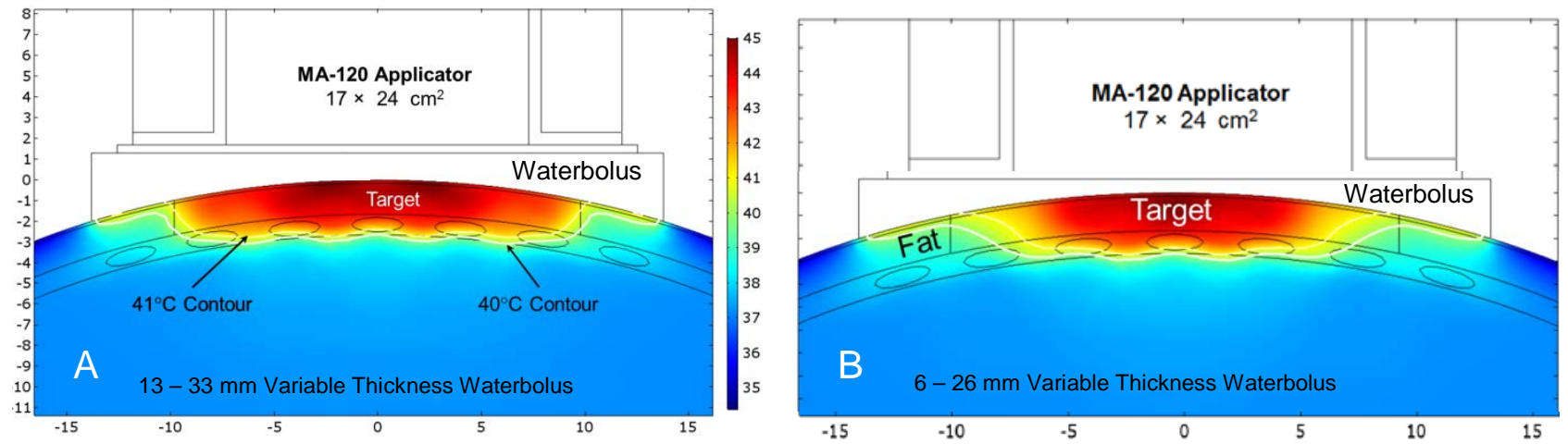

Figure 15 - Numerical simulation of temperature distribution in layered tissue model of human chestwall under the MA120 applicator coupled with conformal variable thickness waterbolus. A) Waterbolus is $1.3 \mathrm{~cm}$ centrally increasing to 3.3 $\mathrm{cm}$ at its outer perimeter $2 \mathrm{~cm}$ beyond the waveguide aperture; B) waterbolus is $0.6 \mathrm{~cm}$ centrally increasing to $2.6 \mathrm{~cm}$ at its outer perimeter ( $2 \mathrm{~cm}$ beyond the waveguide aperture). Note the improved lateral extent of heating obtained by increasing waterbolus thickness by $7 \mathrm{~mm}$.

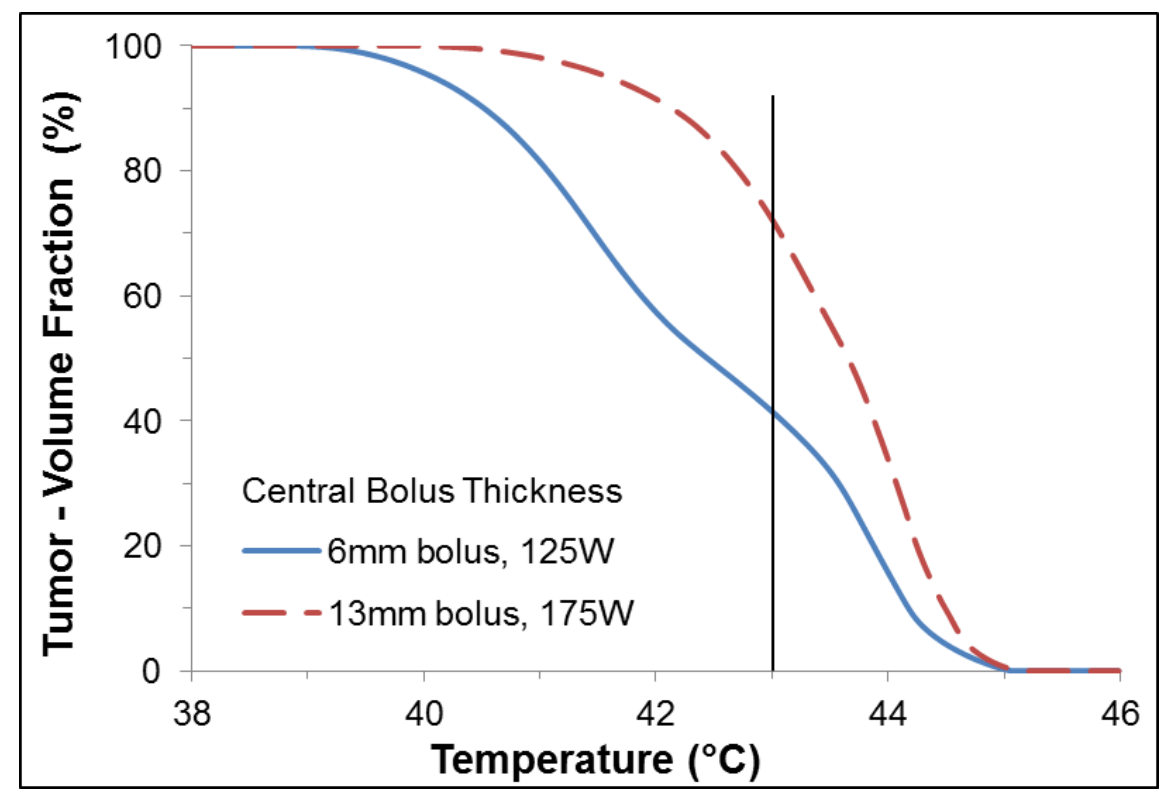

Figure 16 - Simulation of cumulative temperature volume histograms for the two treatment configurations shown in Figure 15. Note the increase in \% coverage of the $433 \mathrm{~cm}^{3}$ tumor target by increasing bolus thickness by $7 \mathrm{~mm}$, which spreads the heating more uniformly across the contoured chestwall region under the MA-120 applicator. 


\section{DISCUSSION AND CONCLUSIONS}

Microwave waveguide applicators have been used for decades to heat superficial tumors within about $3 \mathrm{~cm}$ of the tissue surface. For most clinical users, the heating patterns are considered non-adjustable other than changing microwave power level up/down, or moving the applicator relative to the tumor target. In reality, many factors affect waveguide heating patterns. Some factors are not controllable, such as dielectric and thermal tissue properties, whereas other factors may be adjusted by the user to change the heating pattern during treatment. Changing the temperature of the water coupling bolus has a definitive effect on surface and subcutaneous tissue temperatures. When adjusted appropriately in combination with microwave power level, the bolus temperature will shift the depth of maximum temperature from the surface to $6 \mathrm{~mm}$ or more for practical bolus temperatures, as reported previously. ${ }^{31}$ This study documents the effects of varying several other parameters that are under the control of treatment personnel: i) coupling medium (e.g., air coupled, direct contact, or waterbolus coupled); ii) waterbolus lateral size, thickness, and uniformity of thickness; and iii) rotation of the impedance matching tuning blades.

Experimental models of several treatment configurations of the MA-120 waveguide with various coupling media were constructed to measure SAR patterns in a liquid muscle phantom load. These same models were entered into an electromagnetic simulation software (COMSOL) to calculate SAR patterns for matching configurations. Figure 6 clearly validates the electromagnetic modeling with closely matching experimental SAR pattern measurements in homogeneous muscle load for air coupled, direct contact, and BSD waterbolus coupled treatment configurations. With the COMSOL modeling validated, many more treatment configurations were simulated to determine the effect of varying the above mentioned parameters.

Figures 10 and 11 demonstrate the ability to move the SAR peaks around under the waveguide aperture by varying waterbolus lateral dimensions. Since bolus size is difficult to adjust mid-treatment, this major effect on heating pattern should be pre-planned with advance treatment planning, and/or the bolus size changed between successive heat treatments. Similarly, Figure 9 demonstrates the ability to adjust heating pattern by varying the rotation angle of the tuning blades inside the MA-120 applicator. Unfortunately, optimum tuning blade orientation is determined empirically to provide effective impedance match and is therefore constrained to one optimum rotation angle in order to maintain efficient power transfer to the tissue. Thus, this variable is not available to the operator for optimization of heating pattern during treatment. Although Figure 13 shows only subtle effects for several practical coupling boluses over a homogeneous muscle load, Figure 15 shows the ability to expand the heating pattern significantly in a more realistic layered tissue load by increasing waterbolus thickness by just $7 \mathrm{~mm}$. This major effect of water layer thickness is quantified in the cumulative temperature-volume histograms of Figure 16. These figures demonstrate the difficulty in pre-planning use of specific water layer thicknesses since the impact on heating pattern is dependent on tissue load, coupling media, and tuning blade positions. Regardless, since waterbolus thickness is readily adjusted during treatment by pumping more or less water into the bolus, this waterbolus thickness parameter becomes a powerful tool for the operator to vary heating patterns in real time during treatment. Thus while unlikely that an optimum water thickness can be preplanned and implemented practically in clinical circumstances, it appears possible to improve the quality of heat treatment by varying waterbolus thickness cyclically during treatment to move heat peaks around under the aperture. This should improve the uniformity of thermal dose distribution delivered by the end of a one hour heat treatment while minimizing pain and improving patient comfort. Therefore, the major implication of this work is that the uniformity of thermal dose delivered to a superficial tumor by a waveguide applicator may be improved by cyclic variation to multiple different waterbolus thicknesses, which will redistribute heat peaks around under the aperture during a 60 min treatment. This should facilitate an increase in average microwave power level by proactively shifting heat peaks and nulls around under the aperture and thereby increase minimum thermal dose to the target.

\section{ACKNOWLEDGEMENTS}

The authors would like to acknowledge support from the Thermal Oncology program at Thomas Jefferson University and the Drexel University Co-Op engineering program. 


\section{REFERENCES}

[1] MD Hurwitz, and PR Stauffer, "Hyperthermia, radiation and chemotherapy: the role of heat in multidisciplinary cancer care,” Semin Oncol, 41(6): 714-29 (2014).

[2] MW Dewhirst, PR Stauffer, SK Das, OI Craciunescu, and Z Vujaskovic, Hyperthermia in Clinical Radiation Oncology, ed. L Gunderson and J Tepper, Elsevier, (Philadelphia), 381-398, (2016).

[3] NR Datta, SG Ordonez, US Gaipl, MM Paulides, H Crezee, J Gellermann, D Marder, E Puric, and S Bodis, "Local hyperthermia combined with radiotherapy and-/or chemotherapy: recent advances and promises for the future," Cancer Treat Rev, 41(9): 742-53 (2015).

[4] B Emami, C Scott, CA Perez, S Asbell, P Swift, P Grigsby, A Montesano, P Rubin, W Curran, J Delrowe, H Arastu, K Fu, and E Moros, "Phase III study of interstitial thermoradiotherapy compared with interstitial radiotherapy alone in the treatment of recurrent or persistent human tumors. A prospectively controlled randomized study by the Radiation Therapy Group,” Int J Radiat Oncol Biol Phys, 34(5): 1097-104 (1996).

[5] CA Perez, B Gillespie, T Pajak, NB Hornback, B Emami, and P Rubin, "Quality assurance problems in clinical hyperthermia and their impact on therapeutic outcome: a report by the Radiation Therapy Oncology Group,” Int $\mathrm{J}$ Radiat Oncol Biol Phys, 16: 551-558 (1989).

[6] PR Stauffer, Thermal therapy techniques for skin and superficial tissue disease, in A critical review, matching the energy source to the clinical need, ed. TP Ryan, SPIE Optical Engineering Press, (Bellingham WA), 327-67, (2000).

[7] PR Stauffer, “Evolving technology for thermal therapy of cancer,” Int J Hyperthermia, 21(8): 731-44 (2005).

[8] PR Stauffer, and MM Paulides, Hyperthermia Therapy for Cancer, in Comprehensive Biomedical Physics, ed. A Brahme, Elsevier, (Oxford), pp. 115-151, (2014).

[9] GC van Rhoon, External Electromagnetic Methods and Devices, in Physics of Thermal Therapy: Fundamentals and Clinical Applications, ed. EG Moros, Taylor and Francis, (Boca Ratan FL), 139-158, (2013).

[10] HP Kok, J Gellermann, CA van den Berg, PR Stauffer, JW Hand, and J Crezee, "Thermal modelling using discrete vasculature for thermal therapy: A review,” Int J Hyperthermia, 29(4): 336-45 (2013).

[11] MM Paulides, PR Stauffer, E Neufeld, PF Maccarini, A Kyriakou, RA Canters, CJ Diederich, JF Bakker, and GC Van Rhoon, "Simulation techniques in hyperthermia treatment planning," Int J Hyperthermia, 29(4): 346-57 (2013).

[12] E Neufield, MM Paulides, GC van Rhoon, and N Kuster, Numerical modeling for simulation and treatment planning of thermal therapy, in Physics of Thermal Therapy: Fundamentals and Clinical Applications, ed. EG Moros, Taylor and Francis, (Boca Ratan FL), 119-136, (2013).

[13] G Bruggmoser, S Bauchowitz, R Canters, H Crezee, M Ehmann, J Gellermann, U Lamprecht, N Lomax, MB Messmer, O Ott, S Abdel-Rahman, R Sauer, M Schmidt, A Thomsen, R Wessalowski, and G van Rhoon, "Quality assurance for clinical studies in regional deep hyperthermia,” Strahlenther Onkol, 187(10): 605-610 (2011).

[14] J Muller, J Hartmann, and C Bert, "Infrared camera based thermometry for quality assurance of superficial hyperthermia applicators,” Phys Med Biol, 61(7): 2646-64 (2016).

[15] HD Trefna, H Crezee, M Schmidt, D Marder, U Lamprecht, M Ehmann, J Hartmann, J Nadobny, J Gellermann, N van Holthe, P Ghadjar, N Lomax, S Abdel-Rahman, C Bert, A Bakker, MD Hurwitz, CJ Diederich, PR Stauffer, and GC van Rhoon, "Quality assurance guidelines for superficial hyperthermia clinical trials: I. Clinical requirements,” Int J Hyperthermia: 1-12 (2017).

[16] CC Vernon, JW Hand, SB Field, D Machin, JB Whaley, J van der Zee, WLJ van Putten, GC van Rhoon, JDP van Dijk, D Gonzalez-Gonzalez, FF Liu, P Goodman, and M Sherar, "Radiotherapy with or without hyperthermia in the treatment of superficial localized breast cancer: Results from five randomized controlled trials,” Int J Radiat Oncol Biol Phys, 35(4): 731-44 (1996). 
[17] EL Jones, JR Oleson, LR Prosnitz, TV Samulski, Z Vujaskovic, D Yu, LL Sanders, and MW Dewhirst, "Randomized trial of hyperthermia and radiation for superficial tumors ” Journal of Clinical Oncology, 23(13): 3079-85 (2005).

[18] J Overgaard, D Gonzalez Gonzalez, MCCM Hulshof, G Arcangeli, O Dahl, O Mella, and SM Bentzen, "Randomised trial of hyperthermia as adjuvant to radiotherapy for recurrent or metastatic malignant melanoma," Lancet, 345: 540-543 (1995).

[19] R Valdagni, and M Amichetti, "Report of long-term follow-up in a randomized trial comparing radiation therapy and radiation therapy plus hyperthermia to metastatic lymph nodes in stage IV head and neck patients,” Int J Radiat Oncol Biol Phys, 28: 163-169 (1994).

[20] Y Birkelund, O Klemetsen, SK Jacobsen, K Arunachalam, PF Maccarini, and PR Stauffer, "Vesicoureteral reflux in children: a phantom study of microwave heating and radiometric thermometry of pediatric bladder," IEEE Trans Biomed Eng, 58(11): 3269-78 (2011).

[21] K Arunachalam, PF Maccarini, JL Schlorff, Y Birkelund, S Jacobsen, and PR Stauffer, "Design of a water coupling bolus with improved flow distribution for multi-element superficial hyperthermia applicators," Int J Hyperthermia, 25(7): 554-65 (2009).

[22] CJ Diederich, and PR Stauffer, "Pre-clinical evaluation of a microwave planar array applicator for superficial hyperthermia,” Int J Hyperthermia, 9(2): 227-46 (1993).

[23] DG Neuman, PR Stauffer, S Jacobsen, and F Rossetto, "SAR pattern perturbations from resonance effects in water bolus layers used with superficial microwave hyperthermia applicators," International Journal of Hyperthermia, 18(3): 180-93 (2002).

[24] DB Rodrigues, MD Hurwitz, PF Maccarini, and PR Stauffer, "Optimization of chest wall hyperthermia treatment using a virtual human chest model,” Proc IEEE, 15416614: (2015).

[25] T Drizdal, P Togni, L Visek, and J Vrba, "Comparison of Constant and Temperature Dependent Blood Perfusion in Temperature Prediction for Superficial Hyperthermia,” Radioengineering, 19(2): 281-289 (2010).

[26] KS Cheng, Y Yuan, Z Li, PR Stauffer, P Maccarini, WT Joines, MW Dewhirst, and SK Das, "The performance of a reduced-order adaptive controller when used in multi-antenna hyperthermia treatments with nonlinear temperature-dependent perfusion,” Physics in Medicine and Biology, 54(7): 1979-1995 PMCID: PMC2699754 (2009).

[27] PA Hasgall, F Di Gennaro, C Baumgartner, E Neufeld, MC Gosselin, D Payne, and e al., [ IT’IS database for thermal and electromagnetic parameters of biological tissues], (Version 3.1. October 13, 2016).

[28] T Drizdal, P Togni, L Visek, and J Vrba, “Comparison of constant and temperature dependent blood perfusion in temperature prediction for superficial hyperthermia,” Radioengineering, 19(2): 281-9 (2010).

[29] S Gabriel, RW Lau, and C Gabriel, "The dielectric properties of biological tissues: III. Parametric models for the dielectric spectrum of tissues,” Physics in Medicine and Biology, 41(11): 2271-93 (1996).

[30] FM Waterman, RE Nerlinger, DJ Moylan, 3rd, and DB Leeper, "Response of human tumor blood flow to local hyperthermia,” International Journal of Radiation Oncology Biology Physics, 13(1): 75-82 (1987).

[31] K Arunachalam, PF Maccarini, OI Craciunescu, JL Schlorff, and PR Stauffer, "Thermal characteristics of thermobrachytherapy surface applicators for treating chest wall recurrence,” Phys Med Biol, 55(7): 1949-69 (2010). 


\section{Citation:}

Stauffer PR, Rodrigues DB, Sinahon R, Sbarro L, Beckhoff V, Hurwitz MD: “Using a conformal waterbolus to adjust heating patterns of microwave waveguide applicators”, in Energy-Based Treatment of Tissue and Assessment IX, edited by TP Ryan, Proc. of SPIE, (SPIE Press, Bellingham WA), ISBN 9781510605732, Vol.10066, No.22, pp. 100660N1-15 (2017). http://dx.doi.org/10.1117/12.2252208

\section{Copyright:}

Copyright (2017) Society of Photo-Optical Instrumentation Engineers. One print or electronic copy may be made for personal use only. Systematic reproduction and distribution, duplication of any material in this paper for a fee or for commercial purposes, or modification of the content of the paper are prohibited. 